\title{
MANUAL DE PRÁCTICAS EN EDUCACIÓN FÍSICA EN EDUCACIÓN PROFESIONAL Y TECNOLÓGICA UTILIZANDO LA APLICACIÓN GRATUITA EFE - EPTFIS
}

\section{ARTÍCULO ORIGINAL}

VIANA, Valderi Nascimento ${ }^{1}$, FECURY, Amanda Alves ${ }^{2}$, OLIVEIRA, Euzébio de ${ }^{3}$, DENDASCK, Carla Viana ${ }^{4}$, DIAS, Claudio Alberto Gellis de Mattos ${ }^{5}$

VIANA, Valderi Nascimento. Et al. Manual de Prácticas en Educación Física en Educación Profesional y Tecnológica utilizando la Aplicación Gratuita Efe Eptfis. Centro Multidisciplinario de Conocimiento de revistas científicas. Año 06, Ed. 04, Vol. 05, pp. 65-76. Abril de 2021. ISSN: 2448-0959, Enlace de acceso: https://www.nucleodoconhecimento.com.br/educacion-fisica-es/manual-de-practicas, 10.32749/nucleodoconhecimento.com.br/educacion-fisica-es/manual-de-practicas

\section{RESUMEN}

La aplicación, EFE-EduFisEPT, actúa como apoyo a las actividades escolares de educación física, utilizando la pedagogía histórico-crítica se produce la confrontación del conocimiento científico del profesor con el conocimiento empírico de los alumnos, provocando el desarrollo de una nueva visión y acción en la sociedad. El propósito de este manual es guiar al profesor de educación física sobre los

\footnotetext{
${ }^{1}$ Educador Físico, Especialista en Fisiología del Ejercicio y Nutrición Deportiva (FAMA), Alumno del Programa de Posgrado en Educación Profesional y Tecnológica (PROFEPT IFAP).

${ }^{2}$ Biomédico, Doctor en Enfermedades Trópicas, Profesor e investigador del Curso Médico del Campus Macapá, Universidad Federal de Amapá (UNIFAP).

${ }^{3}$ Biólogo, Doctor en Enfermedades Trópicas, Profesor e investigador del Curso de Educación Física de la Universidad Federal de Pará (UFPA).

${ }^{4}$ Teólogo, Doctor en Psicoanálisis Clínica. Ha estado trabajando durante 15 años con Metodología Científica (Método de Investigación) en la Guía de Producción Científica de estudiantes de Maestría y Doctorado. Especialista en Investigación de Mercado e Investigación centrado en la salud.

${ }^{5}$ Biólogo, Doctor en Teoría e Investigación del Comportamiento, Profesor e investigador del Curso de Grado de Química del Instituto de Educación Básica, Técnica y Tecnológica de Amapá (IFAP) y del Programa de Posgrado en Educación Profesional y Tecnológica (PROFEPT IFAP).
}

RC: 84006

Disponível em: https://www.nucleodoconhecimento.com.br/educacion-fisica- 
contenidos y prácticas para las clases de educación física en EPT y sobre la funcionalidad de la aplicación gratuita EFE - EPTFis. Con su sencilla interfaz, el uso de la aplicación se vuelve fácil y con una funcionalidad intuitiva. Este producto educativo existe como un apoyo para que el maestro desarrolle una educación física más crítica, que entienda al estudiante más allá del ser biológico, es decir, un ser social, político, cultural e histórico. En la que cada clase, el estudiante puede entender que el contenido presentado está vinculado a diversas dimensiones de la realidad, contribuyendo a una visión de la sociedad basada en valores y actitudes hacia el objetivo común: el conocimiento para generar menos exclusiones y discriminaciones.

Palabras clave: Educación Física, Práctica, EPT, Formación

\section{INTRODUCCIÓN}

La aplicación, EFE-EduFisEPT, fue considerada como un apoyo a las actividades escolares de educación física, con el objetivo de trabajar este componente curricular en su totalidad, proporcionando así una formación humana, integral y omnilateral a los estudiantes de secundaria de educación profesional y tecnológica (EPT) (VIANA e DIAS, 2020).

Así, utilizando la pedagogía histórico-crítica, el conocimiento científico del profesor se enfrenta al conocimiento empírico de los estudiantes, causando el desarrollo de una nueva visión y acción en la sociedad (SILVA, 2017; ANDRADE et al., 2020).

Además del apoyo pedagógico, la aplicación sirve como medio para difundir el conocimiento científico, ya que todas las clases se basan en esta forma de conocimiento. Al ser una aplicación, hay una mayor facilidad de acceso desde cualquier parte del mundo (a través de dispositivos de telefonía móvil, tablets, ordenadores y similares), haciendo que este contenido sea accesible, acercando al usuario a la comunidad científica, actualizando sus conocimientos. Anima al usuario

$\mathrm{RC}: 84006$

Disponível em: https://www.nucleodoconhecimento.com.br/educacion-fisica- 
a ser un conocedor y tener un mayor interés por realizar una labor pedagógica diferenciada (SANTOS et al., 2018).

\section{GOL}

Guía al profesor de educación física sobre los contenidos y prácticas para las clases de educación física en EPT y sobre la funcionalidad de la aplicación gratuita EFE EPTFis

\section{MATERIALES Y MÉTODOS}

La aplicación descrita aquí se puede descargar de forma gratuita https://play.google.com/store/apps/details?id=com.ifap.efe (Play Store), exclusivamente para Android. Se puede acceder al contenido completo de forma gratuita en el https://www.edufisept.com.br/.

\section{LA APLICACIÓN Y SUS CONTENIDOS}

\section{LA SOLICITUD}

La aplicación fue diseñada, así como la página web, para dar al profesional que trabaja (o no) con Educación Profesional y Tecnológica (EPT) una herramienta teórica práctica con el fin de contribuir a la formación humana, integral y omnilateral de los estudiantes (VIANA et al., 2020).

El paso a paso que sigue busca facilitar el trabajo de los profesionales que tienen menos afinidad con este tipo de tecnología.

RC: 84006

Disponível em: https://www.nucleodoconhecimento.com.br/educacion-fisica- 
Figura 1 Muestra la interfaz de entrada de la aplicación. Para ver el menú debe deslizar la pantalla de izquierda a derecha.

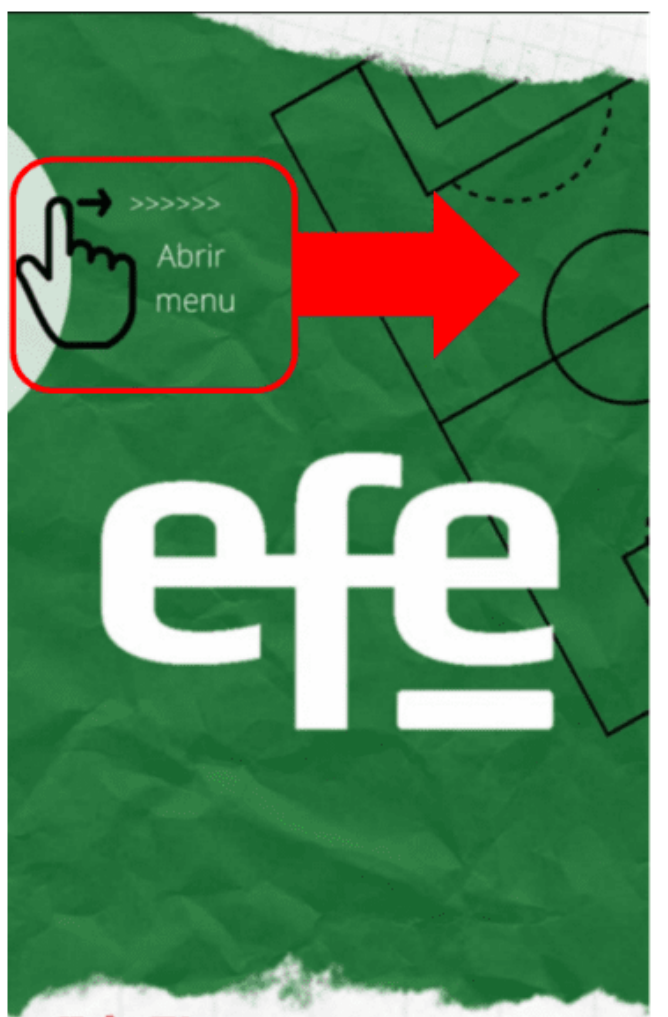

\section{EduFis}

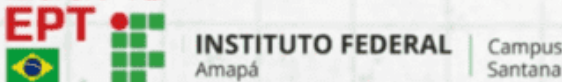

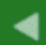

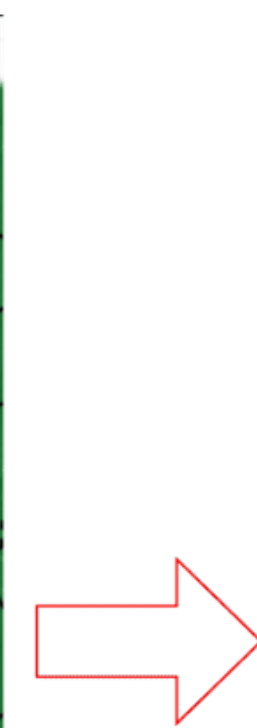

网 Fechar tela

鹿 Feedback

Quem somos

Solabore

D. Sair

m Feedback

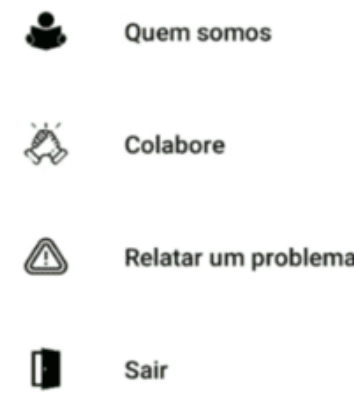

(4) Relatar um problema

\section{EduFis EPT :ä Q}

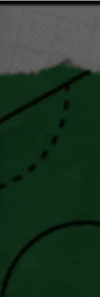

Práticas pedagógicas

4

\section{(2)}

RC: 84006

Disponível em: https://www.nucleodoconhecimento.com.br/educacion-fisica- 
Figura 2 Muestra lo que sucede cuando hacemos clic en "Prácticas pedagógicas" en el menú. Se abre otra pantalla donde puede seleccionar el tipo de práctica.

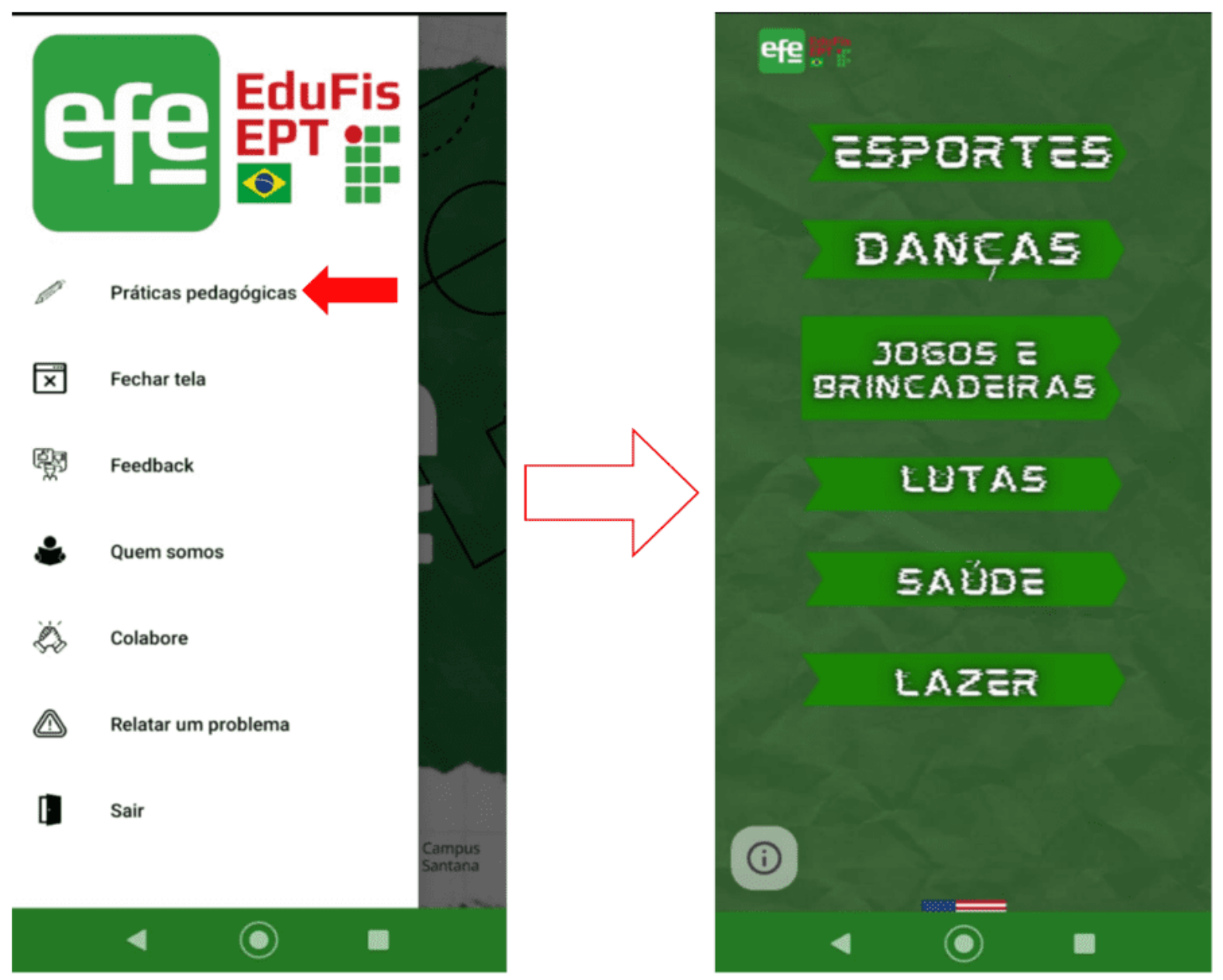

RC: 84006

Disponível em: https://www.nucleodoconhecimento.com.br/educacion-fisica- 
Figura 3 Muestra que al hacer clic en cada elemento, hay botones para acceder a la teoría que lo compone y la práctica en sí, que se llevará a cabo con los estudiantes.

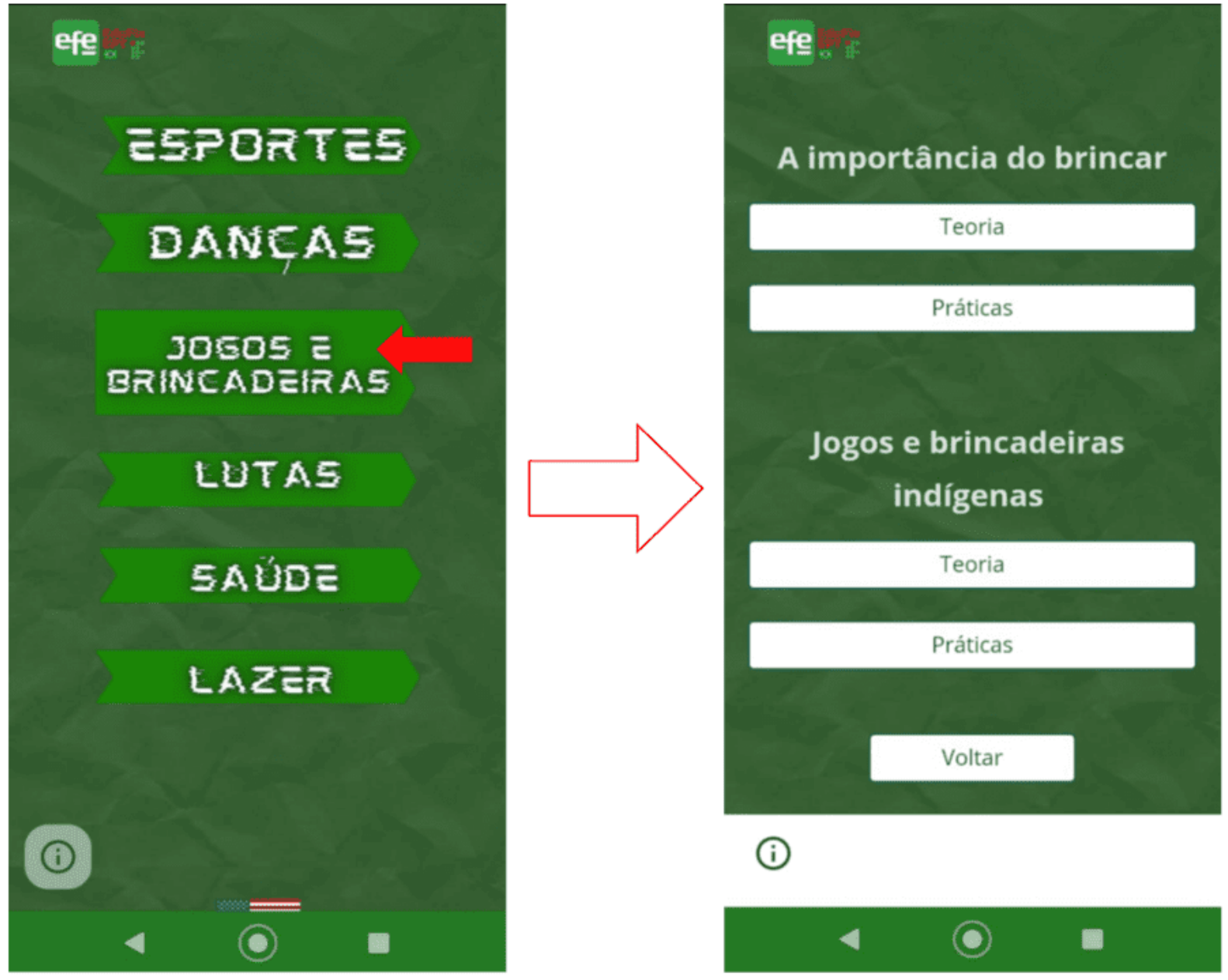

RC: 84006

Disponível em: https://www.nucleodoconhecimento.com.br/educacion-fisica- 
Figura 4 Muestra que al hacer clic en "Teoría", una pestaña se pone a disposición con la teoría razonada y también documentales de vídeo para una mejor comprensión de la parte práctica.

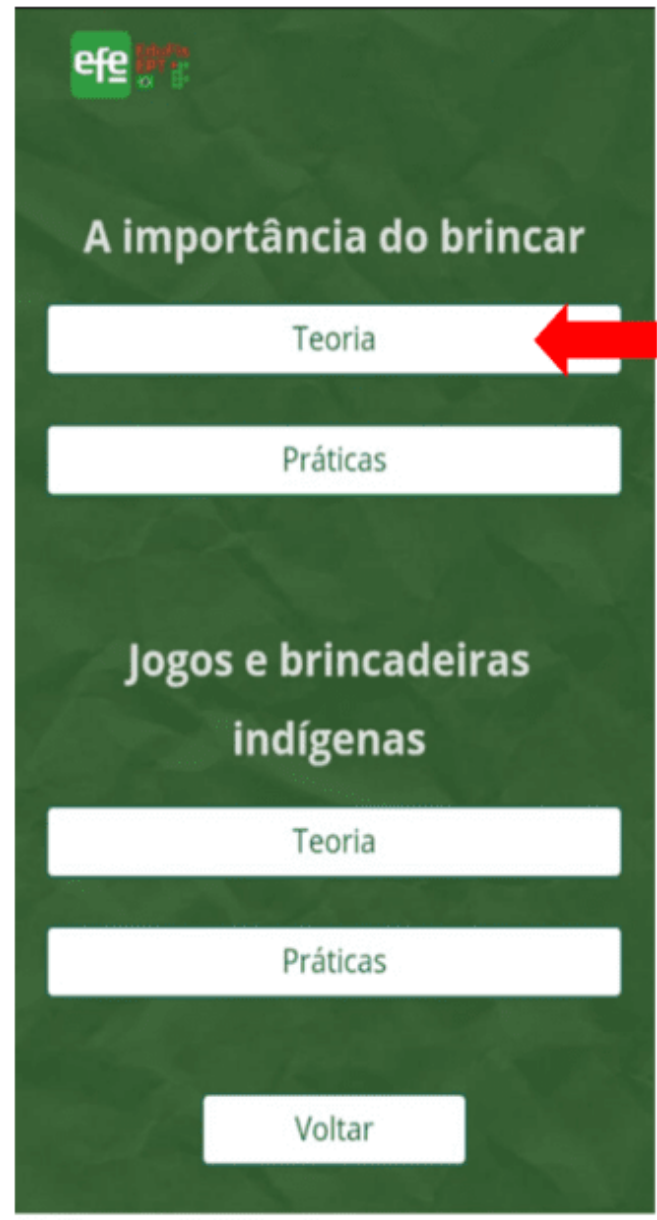

(i)

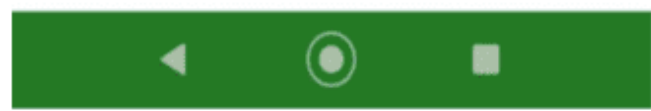

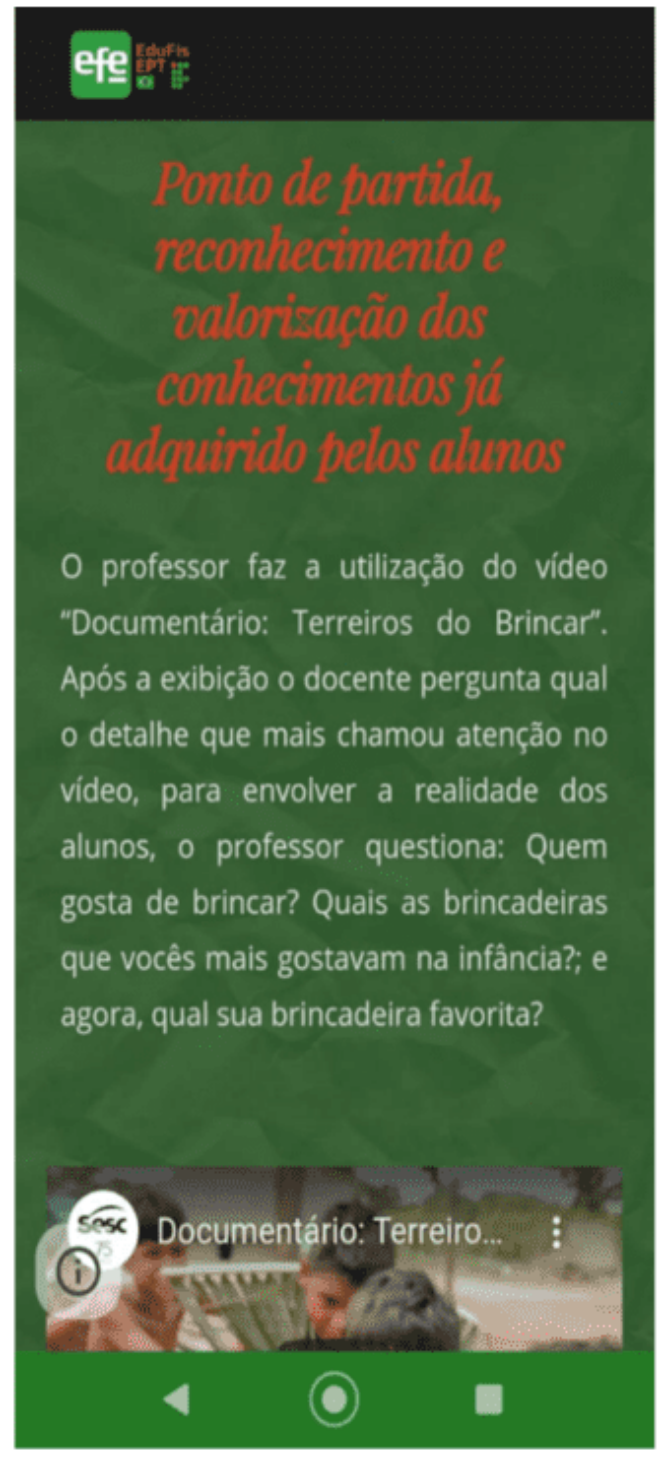

RC: 84006

Disponível em: https://www.nucleodoconhecimento.com.br/educacion-fisicaes/manual-de-practicas 
Figura 5 Muestra que al hacer clic en "Práctica", se abre una nueva pantalla donde se presentan varias prácticas posibles.

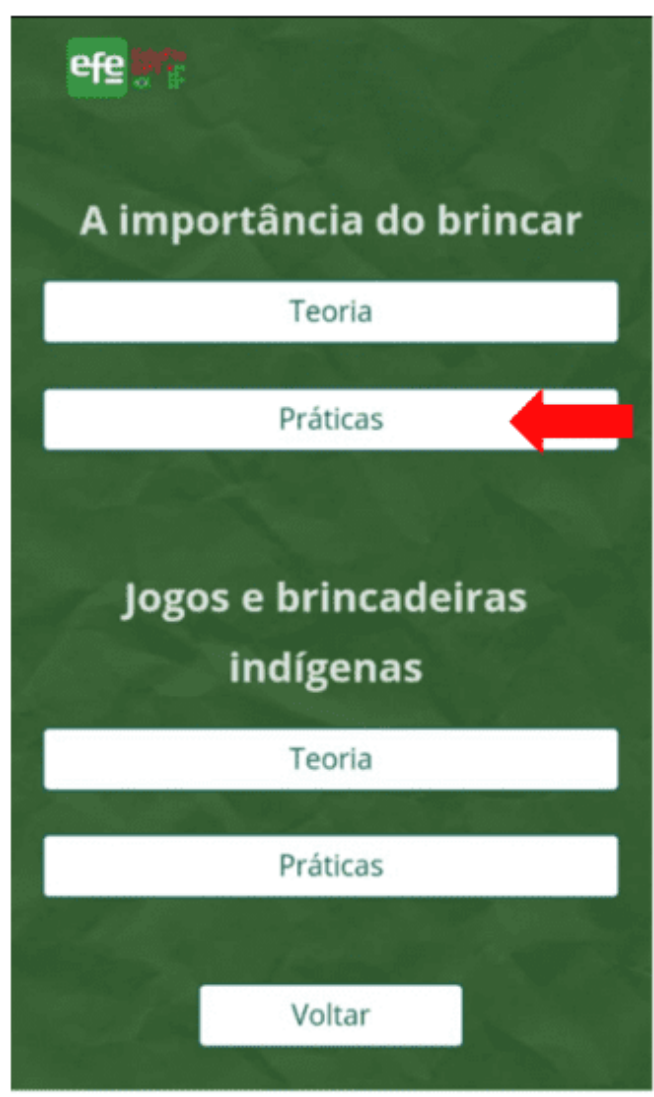

(i)

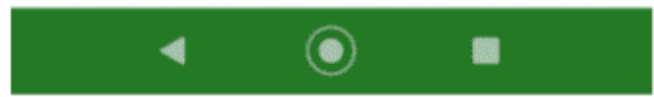

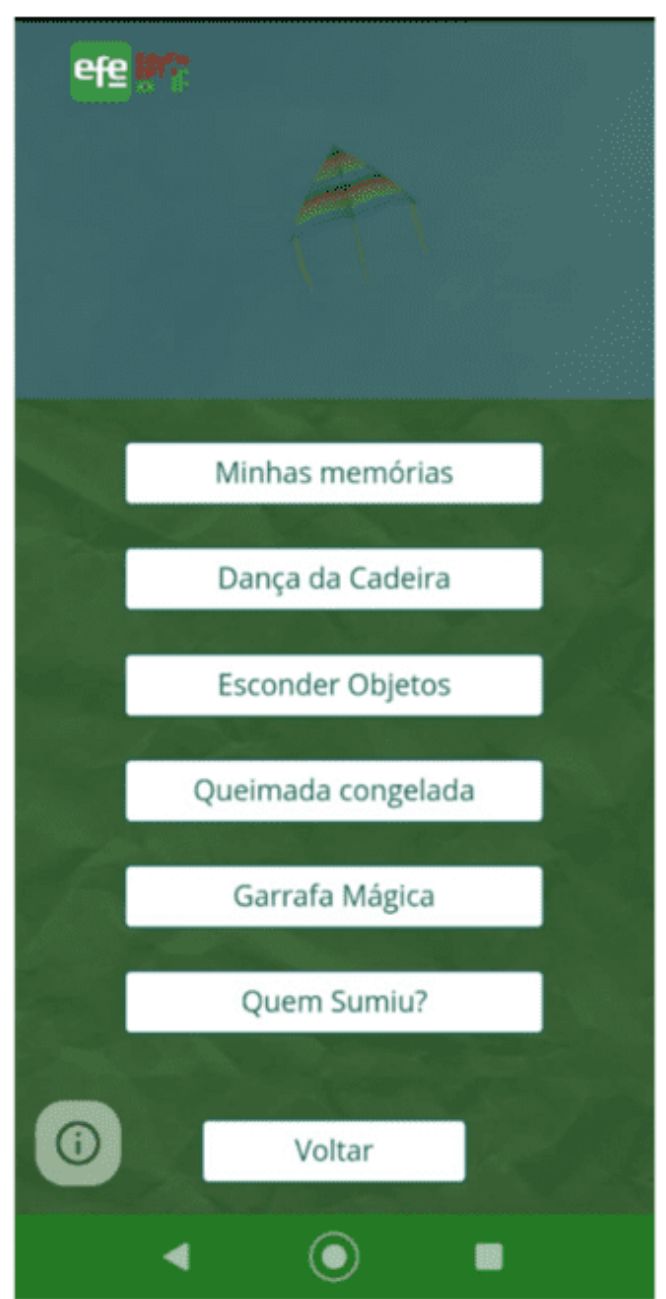

RC: 84006

Disponível em: https://www.nucleodoconhecimento.com.br/educacion-fisicaes/manual-de-practicas 
Figura 6 Muestra que al hacer clic, por ejemplo, en "Queimada congelada" ( "Quemado" ), se abre una nueva pantalla donde para cada práctica hay un elemento que muestra los recursos necesarios para ello, la descripción detallada y una sugerencia útil. Este formato se repite en todas las demás prácticas de aplicación.
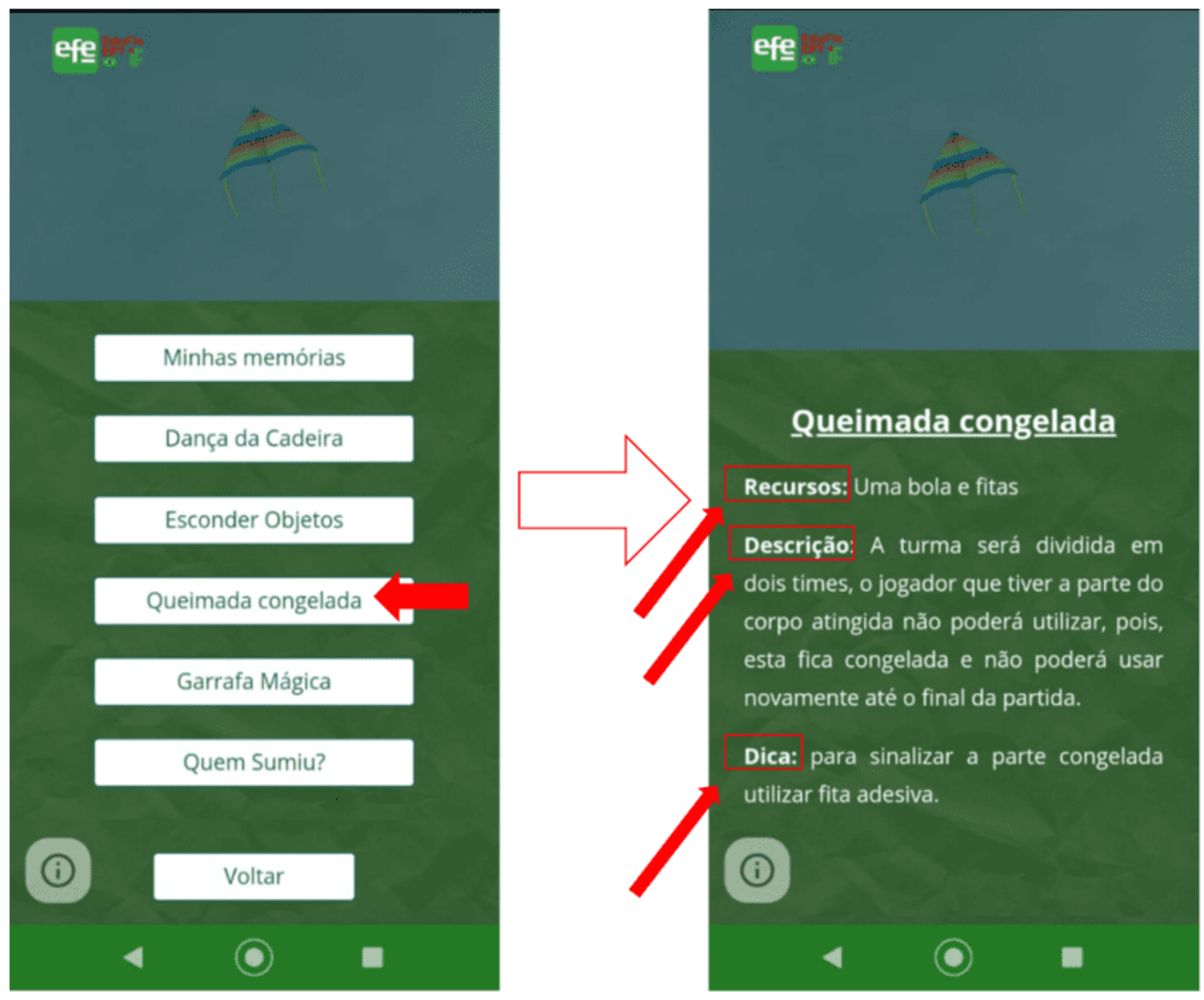

RC: 84006

Disponível em: https://www.nucleodoconhecimento.com.br/educacion-fisica- 
Figura 7 Volver al menú de inicio, haciendo clic en "Feedback", abre una pantalla donde el usuario puede participar en una recopilación de datos, importante para la continuación de la búsqueda del autor de la aplicación, en esta área de conocimiento.

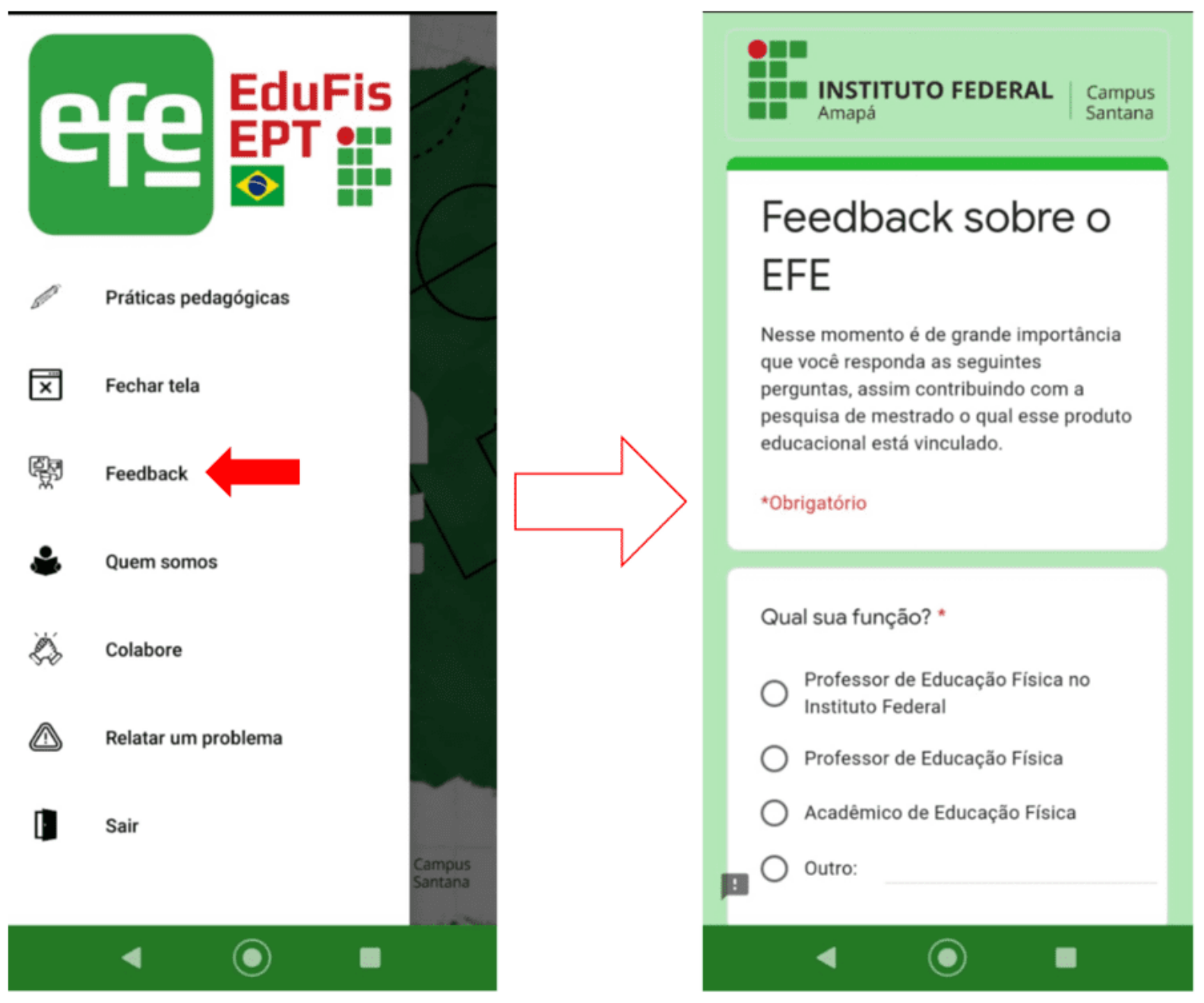

RC: 84006

Disponível em: https://www.nucleodoconhecimento.com.br/educacion-fisica- 
Figura 8 Pulsando el botón "Quiénes somos", todavía en el menú principal, el usuario tendrá acceso a la información de los autores de la aplicación, así como sus currículums en la Plataforma Lattes.
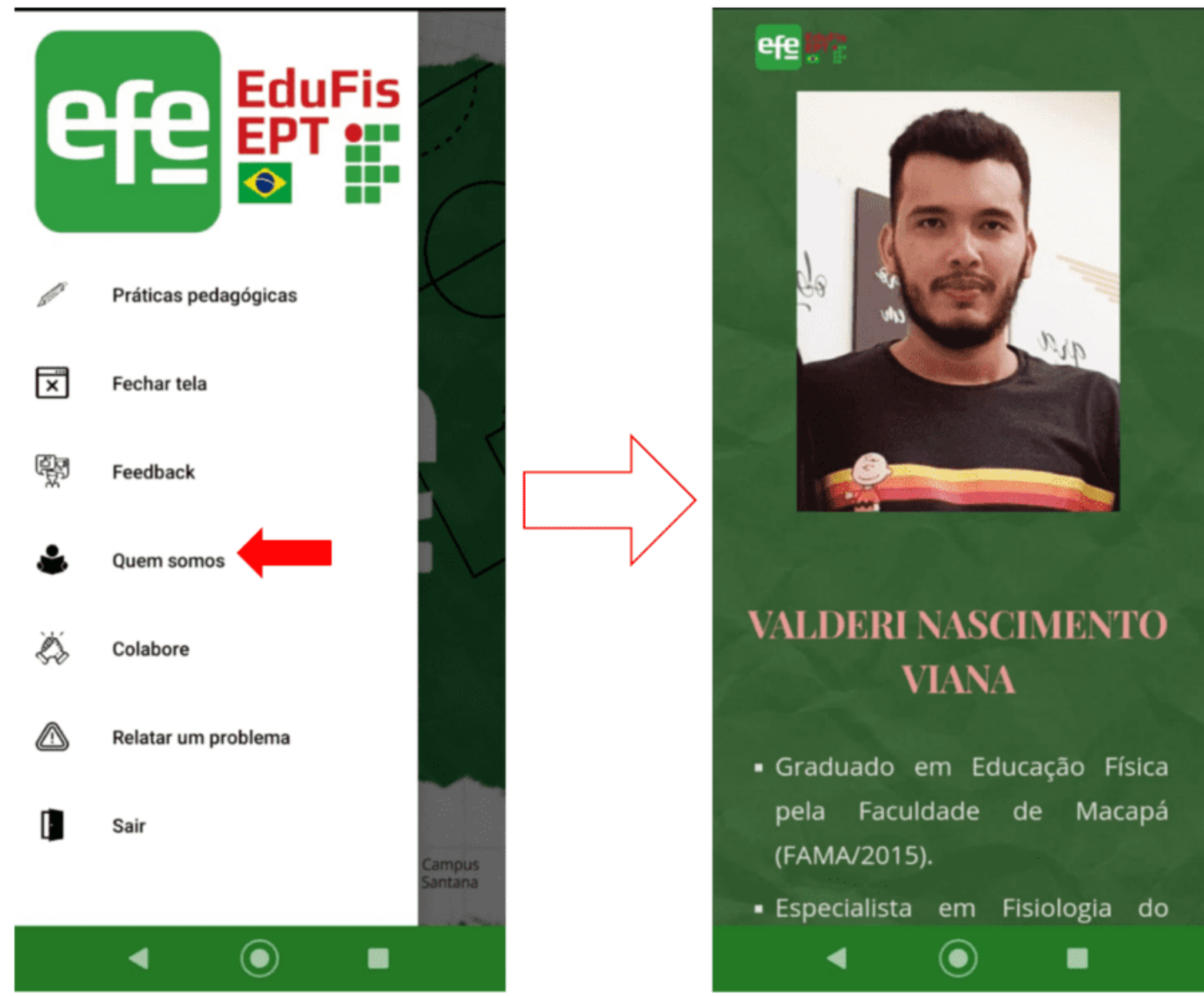

RC: 84006

Disponível em: https://www.nucleodoconhecimento.com.br/educacion-fisica- 
Figura 9 En el menú, haciendo clic en "Colaborar", el usuario puede colaborar en la mejora del conocimiento dentro de esta APP y en el sitio web, enviando en formato PDF o DOC, con su propia práctica pedagógica y con evaluaciones dirigidas por la aplicación. Se tiene en cuenta que el conocimiento no se construye de manera solitaria.
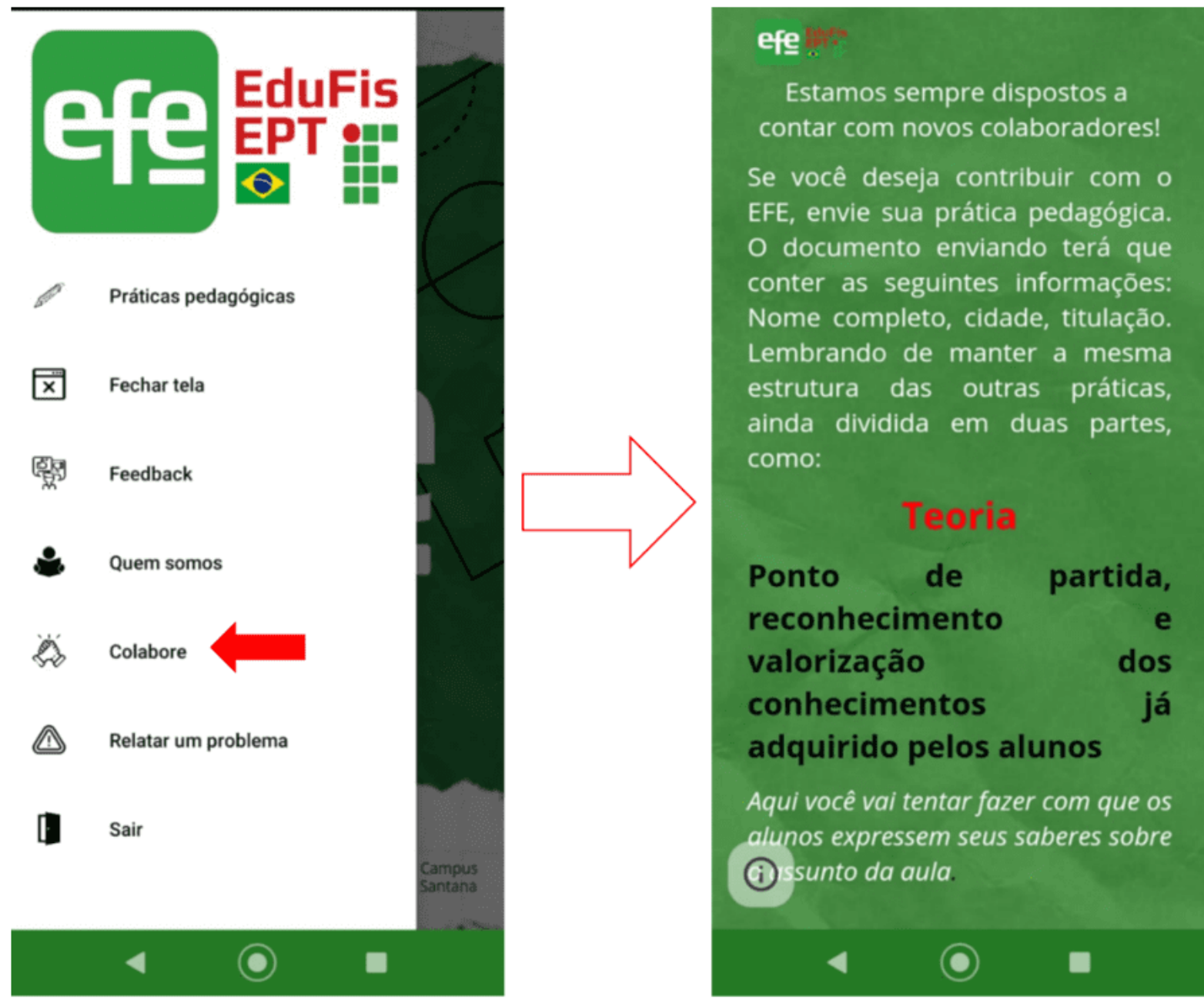

RC: 84006

Disponível em: https://www.nucleodoconhecimento.com.br/educacion-fisica- 
Figura 10 En el menú todavía puede hacer clic en "Informar de un problema" en la aplicación, haga clic en "Cerrar ventana" o incluso haga clic en "Salir".

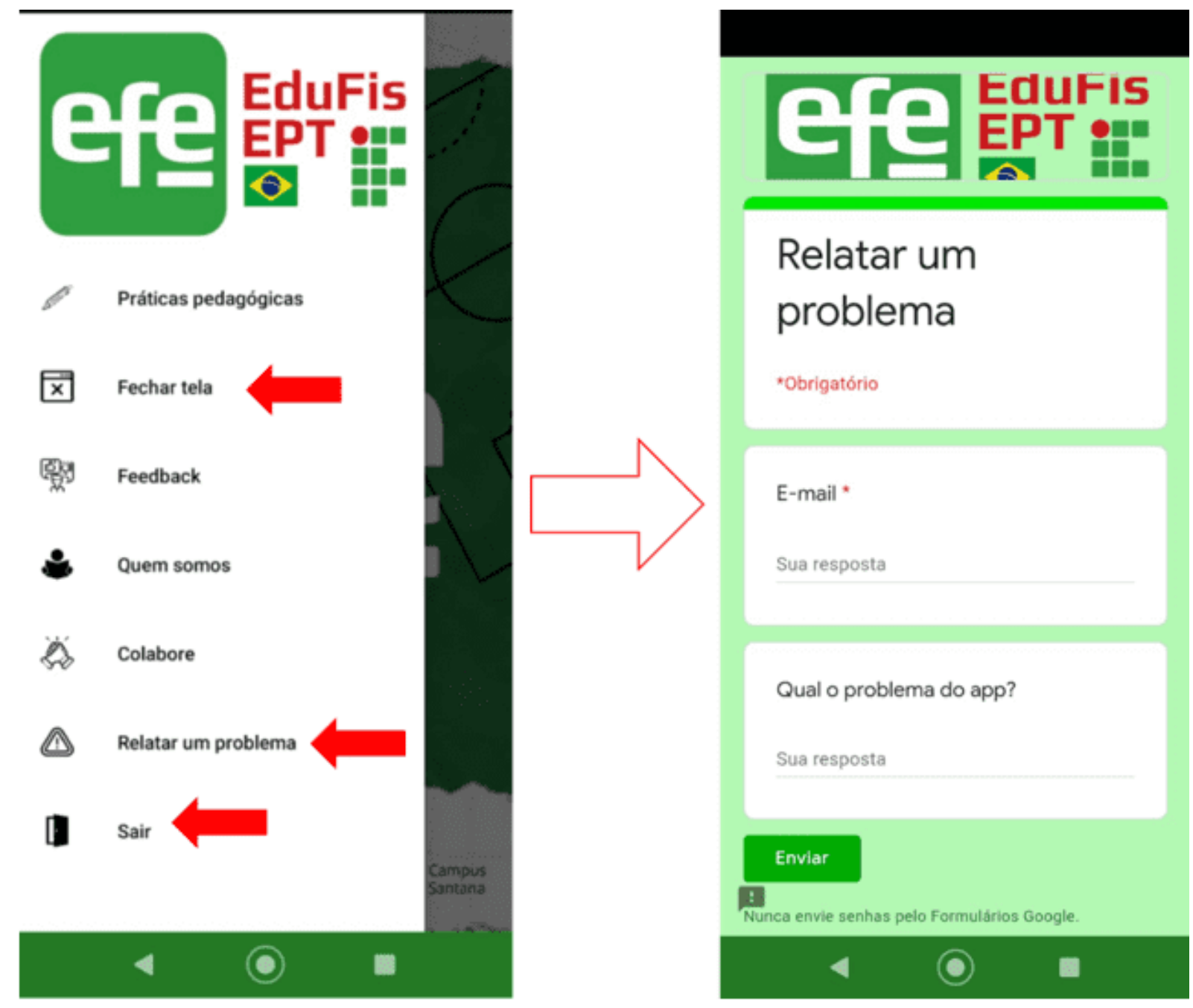

\section{EL CONTENIDO}

Con fácil y rápido acceso a través de la aplicación Android o a través del sitio web, el contenido tiene la ambición de mostrar la parte teórica de la formación humana, integral y omnilateral de toda la actividad práctica disponible.

RC: 84006

Disponível em: https://www.nucleodoconhecimento.com.br/educacion-fisica- 
Para ello, contaba con un marco teórico investigado por el autor durante su programa de postgrado stricto sensu, así como la práctica también derivada de la investigación, muy llevada a cabo a nivel regional.

Figura 11 Muestra parte de la teoría dentro del elemento "Juegos y juegos".

\section{Jogos-e-brincadeiras?l}

Teoriaq

Ponto de partida, reconhecimento 'e valorização dos conhecimentos · já'adquirido pelos alunos

ฯ

O professor faz a utilização do vídeo "Documentário:- Terreiros do- Brincar". (https://www.youtube.com/watch?v=29yJW7XQUws- -). Após· a- exibição- o- docentepergunta qual o detalhe que mais chamou atenção no video, para envolver a realidade dos. alunos, o professor-questiona:-Quem gosta-de brincar?-Quais as brincadeiras que vocêsmais gostavam na infância?; e-agora, qual sua brincadeira favorita?

\section{Como pratica-social, questões que podem'ser resolvidas/debatidas} com o auxilio deste conteúdo. sugestões das dimensões teórico-práticas:-ศा

-Conceitual: O que-são-brincadeiras? -

- Cultural: $\mathrm{O}$ brincar-é-só coisa de criança? -1

RC: 84006

Disponível em: https://www.nucleodoconhecimento.com.br/educacion-fisica- 
-Psicológica/Histórica:-Qual-a-importância-do-brincar?ף

-Social:Por-que na-vida-adulta-somos-obrigados-a esquecer-as-brincadeiras?-

ๆ

Encaminhamento-metodológico para-a-explicação-do-conteúdo

Exibição-integral-ou parcial- do- documentário- "Tarja-Branca". - Disponivel-em. https://www.videocamp.com/pt/campaigns/quarentena-believe-

tarjabranca/player?special_id $=84100 \ldots$

O professor-vai fazer uma reflexão sobre o documentario e abordar assuntos como: brincadeira e a vida adulta; como - mercado-de trabalho-subtrai-das pessoas os momentoslúdicos-e-a-importância-dessa-pratica-para-a-saúde, fazendo-sempre-uma-ligação-com-ovideo exibido -1

\section{Formação,-atitudes-e-valores}

Ao final, o aluno tenha a atitude de perceber que mesmo deixando a infäncia nunca. parou-de-brincar, apenas -mudou- 0 -modo-e formas. Durante essa pratica-trabalha-com-0. aluno-a-cooperação, uniâo, senso-critico-e-criatividade.

RC: 84006

Disponível em: https://www.nucleodoconhecimento.com.br/educacion-fisica- 
Figura 12 Muestra algunas de las prácticas investigadas y descritas dentro del elemento "Juegos y juegos", siempre subdivididos en "Recursos" (necesarios para ensamblar la práctica), "Descripción" (método o regla a seguir para que la práctica funcione) y "Consejo" (siempre otra visión sobre la práctica).

\section{Minhas'memórias \\ I \\ Recursos:-folha-de-A4, canetas}

Descrição: Em sala, -solicitar dos alunos que em uma folha-de-A4 faça um resgate de -suasmemorias as mais antigas, clara e-alegre, momentos de brincadeiras de-sua infäncia. Podeser um brinquedo, um momento-especifico-como: uma-viagem, uma festa, férias. E-comisso, construir-a partir-dessas-lembranças como elas -se-conectam com-sua-vida-atual. -

Dicas:- Caso-0 aluno tenha-algum - registro,-no-grupo- de-WhatsApp-os-alunos-podemmandar a foto junto com um áudio (Possivel ensino remoto), para isso, o professor precisamarcar-um-dia-especifico.- Ou-pode-ser-feito-em-sala-de-aula, - o-qual-cada-um-leva-seuregistro-e-comenta- 9

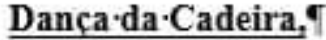

Recursos:-Cadeiras, caixa-de-som

Descrição:- Será-formado - uma-roda-com-as - cadeiras-e- os - alunos-ficarão-a- sua- volta, contendo-uma-cadeira-a-menos que-o-número-de participantes. Ao-som-da-música-osalunos-vão-andar-ao-redor-da-roda-(dançando-no-ritmo-da-música)- Quando-a-músicapausar-cada-integrante-ocupa-uma-cadeira, - sempre-sobrando um-sem, ficando-fora-dadança.-A cada nova rodada fica sempre com uma cadeira a menos até sobrar apenas-umae-dois-alunos, que tentaram ocupá-1a, tornando-se-assim, -0 vencedor. 9

Dica- $\mathrm{O}$ - professor-pode diversificar - como - os alunos-andam - ao redor - da - roda, dandoinstruções como: Mais rápido; mais lento; andar-de costas; mão na cabeça; indo de acordo. com-a-criatividade-do professor. .

RC: 84006

Disponível em: https://www.nucleodoconhecimento.com.br/educacion-fisica- 


\section{Quem·Sumiu?·}

Recursos:-Tecido,-sala-de-aulaf

Descrição:-Em-sala-de-aula-ou-na-quadra-um-aluno-será-escolhido, antes-de-ter-os-olhosvendados, -vai-olhar para-a turma,-logo-depois-ficar-de-costas e-será-vendado, enquantoisso um aluno-selecionado-sai-do-local, 0 -aluno-com 05 -olhos cobertos-vira-de frente paraturma e tira a venda, com isso, terá que adivinhar quem sumiu do local O que estava foraretorna e-ocupa-o-lugar de quem deveria descobrir - o integrante que estava-faltando. -

Dica: $O$-professor-pode autorizar-até-3 - características-do-aluno que-sumiu, tal-duvidasendo respondida pelos-alunos-da-turma-f

\section{Esconder-Objetos,}

Recursos:-20-Bolinhas-de plástico, -1

Descrição:A-turma-será-dividida-em-2-times. Uma-equipe-sai-da-sala-e pela-quadra-oupor-determinado espaço-dentro da-escola-tem que-esconder-os-objetos-(dentro-de-uns-3. minutos). Otime que ficou na-sala aguardando quando autorizado pelo professor -sai paraprocurar-os-objetos, por-um-tempo-limitado-Cada-objeto-encontrado-é-marcado-umapontuação para-o-time, essa pontuação pode-ser-definida pelas-cores-das-bolinhas. -

\section{CONCLUSIONES}

Con su sencilla interfaz, el uso de la aplicación se vuelve fácil y con una funcionalidad intuitiva. Este producto educativo existe como un apoyo para que el maestro desarrolle una educación física más crítica, que entienda al estudiante más allá del ser biológico, es decir, un ser social, político, cultural e histórico. En la que cada clase, el estudiante puede entender que el contenido presentado está vinculado a diversas dimensiones de la realidad, contribuyendo a una visión de la sociedad basada en valores y actitudes hacia el objetivo común: el conocimiento para generar menos exclusiones y discriminaciones.

\section{REFERENCIAS}

RC: 84006

Disponível em: https://www.nucleodoconhecimento.com.br/educacion-fisica- 
ANDRADE, L C; ANDRADE, J.S.D; ALMEIDA S.M. Pedagogia histórico-crítica e Educação Física: o ensino das práticas corporais de aventura nos anos iniciais. Motrivivência, v. 32, n. 63, p. 01-15, 2020.

SANTOS, L. S; PORTO, C. D.; OLIVEIRA, K. E. J. Whatsapp e ciência-a conectividade científica por meio da divulgação. C\&D-Revista Eletrônica da FAINOR, v. 11, n. 2, p. 271-289, 2018.

SILVA, M. B. Contribuições Da Educação Física Escolar Para A Formação Omnilateral Do Ser Social: Uma Reflexão À Luz Da Psicologia Histórico-Cultural E Da Pedagogia Histórico-Crítica. Germinal: Marxismo e Educação em Debate, v. 9, n. 2, p. 249, 2017.

VIANA, V. N. et al. Quadras de esportes em condições de uso adequado no Brasil: influência no ensino-aprendizagem nas aulas de Educação Física (2015). Research, Society and Development, v. 9, p. e239985704-14, 2020.

VIANA, V. N.; DIAS, C. A. G. M. Educação Física e EPT. São Paulo SP: Centro de Pesquisa, 2020. 45p. Disponível em: < https://www.nucleodoconhecimento.com.br/livros/educacao/educacao-fisica-e-ept >.

DOI: 10.32749///educacao/educacao-fisica-e-ept ISBN: 978-65-86069-90-7

Enviado: Abril de 2021.

Aprobado: Abril de 2021.

RC: 84006

Disponível em: https://www.nucleodoconhecimento.com.br/educacion-fisica- 